\title{
Evaluation of MODIS-Derived LST Products with Air Temperature Measurements in Cyprus
}

\author{
A. M. Georgiou ${ }^{a}$ ID, S. T. Varnava ${ }^{b}$ \\ ${ }^{a}$ Enalia Physis Environmental Research Center (ENALIA), Acropoleos 2, 2101 Aglanzia, Nicosia, Cyprus \\ ${ }^{b}$ Department of Geography, University of the Aegean University Hill, Mytilene 81100, Greece
}

\section{Article Info:}

Received: 19 Sept 2018

in revised form: 10 April 2019

Accepted: 30 April 2019

Available Online: 30 August 2019

\section{Keywords:}

MODIS, Land Surface Temperature,

Air Temperature, Regression

analysis, Cyprus

\section{Corresponding Author:}

Andreas Georgiou

Enalia Physis Environmental

Research Centre, Acropoleos 2, 2101

Aglanzia, Nicosia, Cyprus

Email:

a.georgiou@enaliaphysis.org.cy

\begin{abstract}
Air temperature data is usually obtained from measurements made in meteorological stations, providing only limited information about spatial patterns over wide areas. The use of remote sensing data can help overcome this problem, particularly in areas with low station density, having the potential to improve the estimation of air surface temperature at both regional and global scales. Land Surface (skin) Temperatures (LST) derived from Moderate Resolution Imaging Spectroradiometer (MODIS) sensor aboard the Terra and Aqua satellite platforms provide spatial estimates of near-surface temperature values. In this study, LST values from MODIS are compared to ground-based near surface air $\left(T_{\text {air }}\right)$ measurements obtained from 4 observational stations during 2011 to 2015, covering coastal, mountainous and urban areas over Cyprus. Combining Terra and Aqua LST-8 Day and Night acquisitions into a mean 8-day value, provide a large number of LST observations and a better overall agreement with Tair. Comparison between mean monthly LSTs and mean monthly Tair for all sites and all seasons pooled together yields a very high correlations $(r>0.96)$ and biases ranging from $1.9^{\circ} \mathrm{C}$ to $4.1^{\circ} \mathrm{C}$. MODIS capture overall variability with a slightly systematic overestimation of seasonal fluctuations of surface temperature. For the evaluation of intra-seasonal temperature variability, MODIS showed biases up to $6.7^{\circ} \mathrm{C}$ in summer with a tendency to overestimate the variability while in cold seasons, limited biases were presented $\left(0.10^{\circ} \mathrm{C} \pm 0.50^{\circ} \mathrm{C}\right)$ with a tendency to underestimate the variability. Finally, there was no indication of tendency for MODIS to systematically under- or overestimate the amplitude of the inter-annual variability analysis. The presented high standard deviation can be explained by the influence of surface heterogeneity within MODIS $1 \mathrm{~km}^{2}$ grid cells, the presence of undetected clouds and the inherent difference between LST and $T_{\text {air. }}$ Overall, MODIS LST data proved to be a reliable proxy for surface temperature and mostly for studies requiring temperature reconstruction in areas with lack of observational stations.
\end{abstract}

Copyright (C) 2019 GJGP-UNDIP This open access article is distributed under a Creative Commons Attribution (CC-BY-NC-SA) 4.0 International license.

How to cite: Georgiou, A., \& Varnava, S.T. (2019). Evaluation of MODIS-derived LST products with air temperature measurements in Cyprus. Geoplanning: Journal of Geomatics and Planning, 6 (1), 1-12. doi:10.14710/geoplanning.6.1.1-12.

\section{INTRODUCTION}

Land Surface Temperature (LST) consist a key parameter in the physics of land surface processes as controls the exchange of long wave radiation between surface and atmosphere at local through global scales (Li et al., 2013; Anderson et al., 2008). It is an important climatological variable (Ermida et al., 2014) as well as diagnostic parameter of land surface conditions. It plays a crucial role in the surface energy balance, and as such it has been used in evapotranspiration (Anderson et al., 2008; Kustas and Norman, 1996), to infer surface heat fluxes (Caparrini et al., 2004), to desertification processes (Wan et al., 2004), soil moisture (Nemani et al., 1993) vegetation properties (Ermida et al., 2014), near-surface meteorology (Anderson et al., 2008; Crosson et al., 2012) and weather forecasting (Vancutsem et al., 2010).

Meteorological measurements provide accurate temporally discrete temperature information but have limited ability to describe its spatial heterogeneity over large areas. Compensation for this paucity of information may be obtained my various methods of interpolation between known sites. Even these methods proved to be successful in estimating temperatures near meteorological stations with low errors (Florio et al., 2004; Anderson, 2002; Mostovoy et al., 2006), however they suffer from arbitrary location of weather stations (Caparrini et al., 2004) and often lack of near real-time data accessibility. Regardless of the method, interpolation accuracy is highly dependent on station network density and the scale of spatial and temporal 
variability of the parameter (Caparrini et al., 2004). Moreover, the measurements are frequently interpolated with significant errors associated and often lead to unrepresentative spatial patterns (Benali, et.all 2012).

The use of remote sensing data can greatly improve the estimation of LST, fill the gaps on spatial and temporal information thus improving the knowledge of both climate and terrestrial biological processes at regional and global spatial scales (Benali et al., 2012). In regions where the density of meteorological stations is sparse and the data is unavailable, remote sensing can be an important and valuable source information that uniquely resolve these difficulties (Georgiou \& Akçit, 2016). The launch of the Moderate Resolution Imaging Spectroradiometer (MODIS) on board Aqua and Terra has made it possible to get spatial estimates of land surface temperature at high temporal (daily) and spatial resolution $(1 \mathrm{~km})$ across the world. However, satellite data first need to be validated with in situ measurements in order to determine their suitability as a proxy for ambient surface temperature in large scale environments.

Such validation has been carried out in several studies worldwide. Yu et al. (2014) evaluates MODIS LST products using longwave radiation measurement data from observation sites in the northern arid region of China, while Vancutsem et al. (2010) explore different approaches to retrieve high-resolution temperature from MODIS data over different ecosystems. Some others validate satellite derived data using long-term night-time ground measurements (Zhu et al., 2013) or compare MODIS derived land surface temperatures with ground surface and air temperatures measurements in a continuous permafrost terrain (Benali et al., 2012; Zhu et al., 2013; Hachem et al., 2012). Bernardello et al. (2016) use similar method approach for comparison remote-sensing and in situ data in near shore habitats. Finally, Hengl et al. (2011) present a procedure to interpolate daily mean temperature over a period by using time series of auxiliary predictors.

However, up to now there is still considerable lack of relevant scientific works regarding the greater area of Cyprus. The main purpose of this paper is to utilize LST Level-3 8-day records from the Moderate Image Spectrometer (MODIS) on-board both Terra and Aqua satellites to investigate the land surface temperature regime over the Cyprus Island and their comparison with ground-based near surface air $\left(T_{\text {air }}\right)$ measurements obtained from observational stations. The study will thus contribute to the assessment of annual and seasonal surface temperature variations and the identifications of any anomalies. The framework comprises a combination of already established methods and tools for LST calibration and estimation, statistics and visualization techniques. Geographical Information Systems (GIS) has been chosen as an integrated platform for analysis, modelling and presentation of the results in a combination with Visual Basic programming language as a maintainable and formulation tool. The rest of paper is organized as follows. Section 2 is devoted to the description of the studied area and the methodological approach, the description of in situ data from the observational stations and the satellite imagery that used. In addition, the numerical model configuration and simulation set-up are presented. A presentation and illustration of the model results is given in Section 3 and finally, the paper concludes with Section 4 were the main results are summarized and future work aspects are discussed.

\section{DATA AND METHODS}

\subsection{Study area}

The island of Cyprus is located in the Eastern part of the Mediterranean Sea and particular in the Levantine basin. Cyprus has a typical eastern Mediterranean climate: the combined temperature-rainfall regime is characterized by cool-to-mild wet winters and warm-to-hot dry summers (Michaelides et al., 2009). The island can be divided into five main morphological regions: (i) The mountainous complex of Troodos located at the center of Cyprus; (ii) the mountain range of Pentadaktylos at the northern part; (iii) the central plain of Mesaoria which is located between of these two mountainous ranges; (iv) the hilly areas around the mountainous complex of Troodos; and (v) the coastal plains (Figure 2).

\subsection{Methodological framework}

The presented methodological framework involves a coherence of several stages. More specific, the first step is to define and gather both satellite imagery and ground measurements that needed for the analysis in order to build the digital geo-database. The volume of the data must be organized, filtered and renamed in order to set up a sequence of data accordingly the derived satellite and the time that data gathered corresponding to in situ data. The next step is to calculate the statistics of the data and apply the analysis procedure and, the final step is to visualize the final results. 
Figure 1 provides a schematic diagram of the proposed GIS based methodology with the operational functions that performed through it. Formats for data in this figure are presented with different symbols, and are denoted at the bottom of the figure. Double-lined rectangles represent the two main functions that developed: (a) the regression analysis function where the relationship among MODIS-derived LST and Tair measurements investigated in the terms of overall and inter-seasonal variability, and (b) the regression analysis in terms of inter-annual variability in addition with the production of anomaly land surface temperatures (ALST) maps. A more detailed methodology description is illustrated in next sub-section.

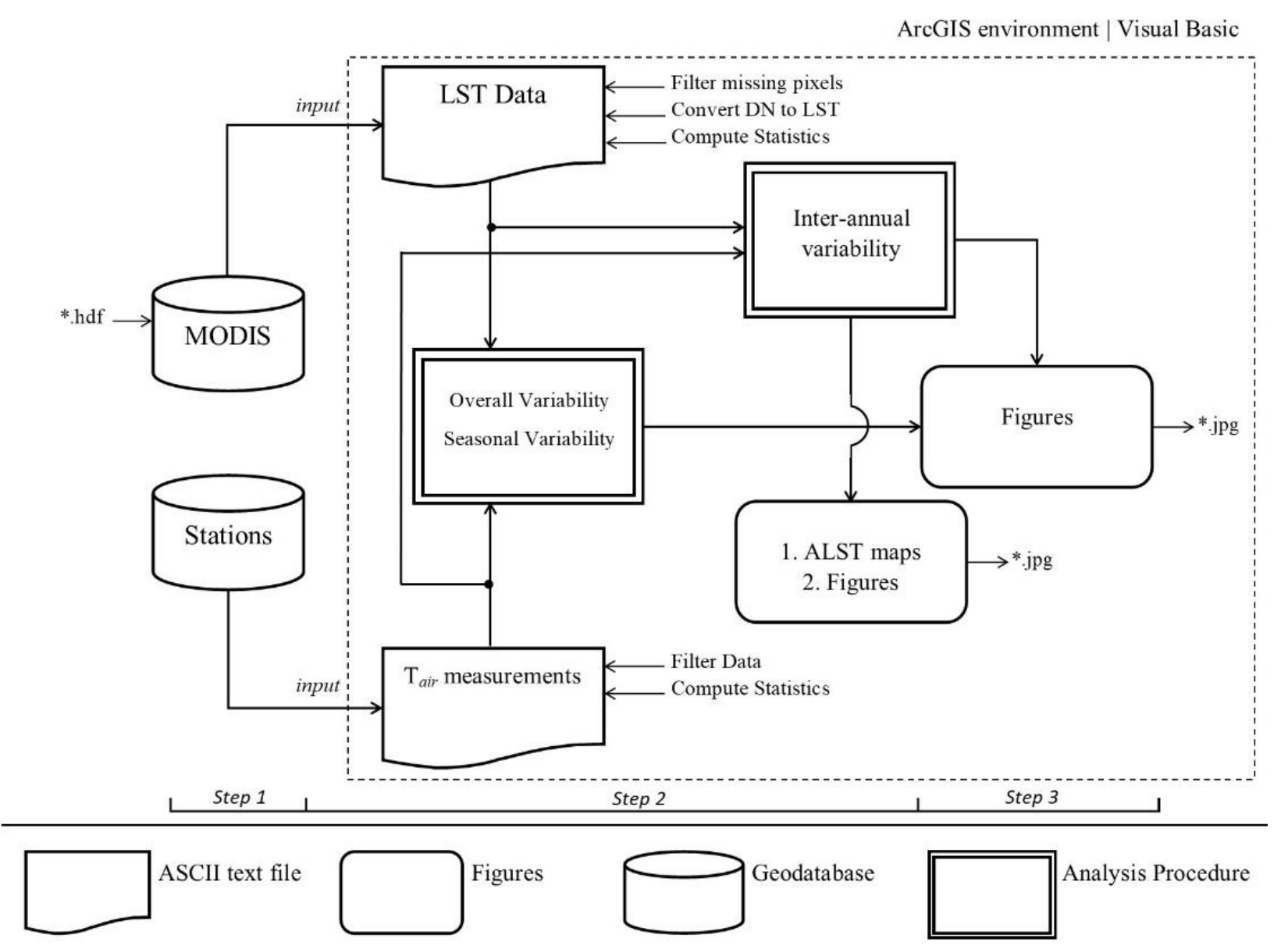

Figure 1. Schematic diagram of processes performed with the developed tool

The ArcGIS ${ }^{T M}$ software system was used for the process, analysis, display and quality control of the MODIS data. In addition, Visual Basic programming language was used to develop supporting tools in order to deliver robust, maintainable and scalable solutions in the analysis. The innovation of this work derives from the proposed modelling of the entire methodology, which combines different tools providing a versatile platform of analysis and semi-automation of the operation, which might also extended into fully automated. Additionally, there are no similar studies over the study area that investigate the LST and compare in situ data with satellite derived imagery thus the results would be very helpful for the local science community.

\subsection{Ground measurements}

The daily $T_{\min }, T_{\max }$ and $T_{\text {avg }}$ data measured at $1.2 \mathrm{~m}$ above the ground for 4 meteorological stations (Table 1) between 2011 and 2015. It has to be noted that only these 4 stations provide coherence measurements over study area for the examined time period. In addition, some stations are missing data due to cloudy days or malfunction of the data loggers and removed from further analysis. The Tair range from -5.0 to $33.0^{\circ} \mathrm{C}$ with a data logger accuracy of $\pm 0.50^{\circ} \mathrm{C}$ as reported by the manufacturer. The data source of the data is the Department of Meteorology of Cyprus which is part of the organizational structure of the Ministry of Agriculture, Rural Development and Environment.

Daily $T_{\text {air }}$ logger data were aggregated to obtain mean 8-day series period surface temperature in order to have comparable time steps between data loggers and satellite derived data. However, several factors 
may influence measurement bias; Vogt et al. (1997) stated to the changes on instrumentation, station location and the surrounding environment. Moreover, according to Benali et al. (2012), the heterogeneity related with the observation time and the differences of data aggregation methodology at different temporal scales (e.g. hourly to daily) can have a significant impact on the quality and inter comparability of measured data.

Table 1. Information of validation stations

\begin{tabular}{|clccccccc} 
No & Station Name & Code & St.No & Elev. $(\mathrm{m})$ & Days & Lat. & Long. & Characteristics \\
\hline $\mathbf{1}$ & PAFOS (AIRPORT) & PF & 82 & 10 & 1815 & $34^{\circ} 43^{\prime}$ & $32^{\circ} 30^{\prime}$ & Coastal area \\
\hline $\mathbf{2}$ & ATHALASSA & ATH & 666 & 162 & 1776 & $35^{\circ} 09^{\prime}$ & $33^{\circ} 24^{\prime}$ & Urban area \\
\hline $\mathbf{3}$ & LARNACA (AIRPORT) & LCA & 731 & 1 & 1826 & $34^{\circ} 53^{\prime}$ & $33^{\circ} 38^{\prime}$ & Coastal area \\
\hline $\mathbf{4}$ & PRODROMOS & PR & 225 & 1380 & 1763 & $34^{\circ} 57^{\prime}$ & $33^{\circ} 38^{\prime}$ & High vegetation \\
\hline
\end{tabular}

The distribution of the meteorological stations that used highlight two coastal regions (Pafos and Larnaca stations), one mountainous region at an elevation of $1380 \mathrm{~m}$ a.s.l. (Prodromos station) with high vegetation that exposed to snow during winter period and one with low vegetation in urban area (Athalassa station). Although station density influences the spatial distribution of uncertainty it highlights the regions where the Tair estimation based on remote sensing can potentially provide a higher added value. Figure 2 presents the distribution of the observational stations over the Island in an averaged LST base map as derived from MODIS/Terra and MODIS/Aqua data of 2015.

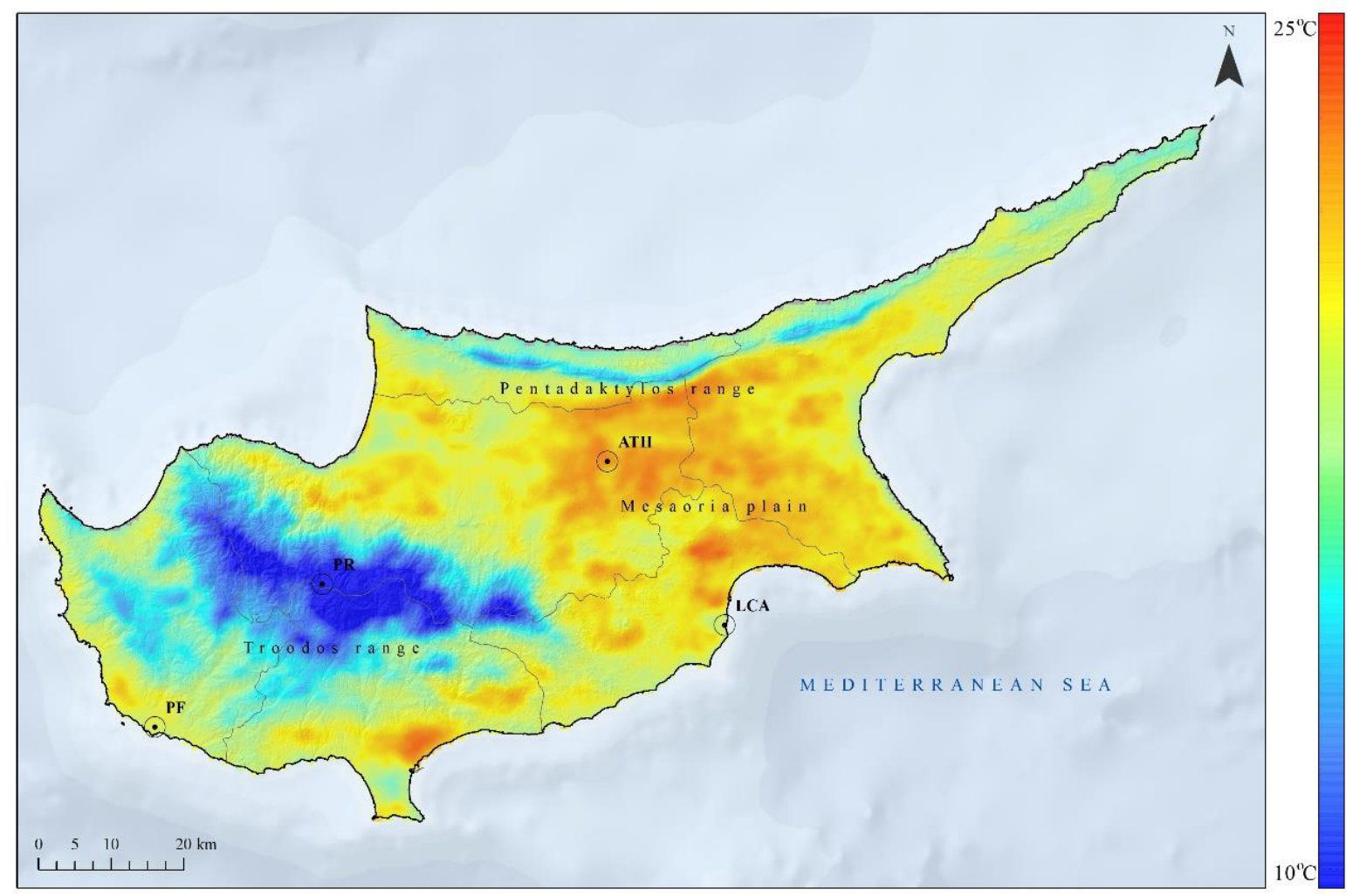

Figure 2. Distribution of observational meteorological stations over Cyprus with average LST for 2015 as a base map. Information about stations can be found in Table 1

\subsection{MODIS LST data and process}

The LST dataset that used was derived from MODerate-resolution Imaging Spectroradiometer (MODIS) instrument on board both Aqua and Terra sun synchronous satellites. The MODIS/Terra and MODIS/Aqua Land Surface Temperature products provide per-pixel temperature and emissivity values in a sequence of swath-based to grid-based global products. The MODIS/Terra and MODIS/Aqua LST Thermal 8-day L3 (MOD11A2 and MYD11A2) of spatial resolution of $1 \mathrm{~km}$ which configured on a $0.05^{\circ}$ latitude/longitude climate modeling grid (CMG) are used. This version of MODIS LST has a significant improved spatial coverage, 
stability and accuracy when compared with previous versions (Wan, 1999). This product retrieves LST with an error lower than $1{ }^{\circ} \mathrm{C}\left( \pm 0.70^{\circ} \mathrm{C}\right.$ standard deviation) in the range of -10 to $50^{\circ} \mathrm{C}$, assuming that the surface emissivity is known (Wan, 2008). According to Benali et al. (2012), the validation of the LST algorithm showed errors lower than $10 \mathrm{C}$ over homogeneous surface such as water, crop and grassland surfaces.

The satellite image database consists of LST 8-day data obtained from NASA Ocean Color web servers (Ocean Color Web) in Hierarchical Data Format (HDF). In order to eliminate low quality data because remote sensing based Tair estimations are strongly influenced by errors on the LST retrievals, a good quality flag (QL0 ) was chosen which include sun glint mask and sea contaminations. The application of this flag increases the reliability of LST estimation (Georgiou \& Akçit, 2016). A total of 920 images corresponded of a 5-year period (2011 - 2015) for day and night were used. Hachem et al. (2012) suggest this combination of all MODIS LSTs available in order to produce accurate LST maps. Note that for Terra satellite the ascending (Day) local equatorial crossing time is 10:30 and descending (Night) is 22:30 while in Aqua satellite is 13:30 and 01:30 respectively. The twice-daily temporal resolution is also very important as allows to monitor the evolution of surface temperatures throughout the year. At the pixel scale, variations in topography, surface materials, vegetation and snow cover can influence the temperatures measured from space-borne thermal sensors (Hachem et al. 2012). So, there is the assumption that LST values correspond to the $1 \mathrm{~km}^{2}$ pixel footprint, taking into account potential geo-location errors of up to $50 \mathrm{~m}$ for the center of the footprint and some variations in footprint area (Hachem et al., 2012). These small errors can contribute to overall LST. Thus, MODIS pixels centered to on or located close to the selected meteorological stations. The presence of water bodies of different sizes in the proximity of some stations can result a mixed MODIS pixel over a given station.

The steps that followed for the estimation of LST from satellite data includes layer selection, radiometric correction, geo-referencing, LST calculation, land mask and cloud contamination. These steps may overlap or interact among them without estimating false values of LST (Georgiou \& Akçit, 2016). More specific, the first step is to build the digital geo-database and rename the volume of data in order to set up a sequence accordingly the derived satellite and the time that data gathered. The next step is to select the correct layer of data, apply the mask of the study area and exclude the false values of sea (pixels contained over $75 \%$ of land are chosen) and clouds from the analysis to eliminate calculation errors. Afterwards, for better visualization results data re-projected in Mercator projection (Georgiou \& Akçit, 2016). The final step is to convert the Digital Number (DN) values of the image into LST values. The calculation of LST values from the DN values can be calculated using Eq.1.

$$
\mathrm{LST}=\mathrm{a} * \mathrm{DN}-\mathrm{K}
$$

Where $\mathrm{a}$ is the scale factor (0.02), DN the digital number values and $\mathrm{K}$ the Kelvin temperature unit (273.15) (Wan, 1999).

\subsection{Data analysis and statistics}

Data from the observational stations used to characterize the general spatio-temporal patterns of the study locations. Then a comparison of the in situ Tair time series with remote-sensing derived LST data throughout the deployment period for each location performed. Differences between MODIS and in situ data in reproducing overall variability, inter-seasonal and inter-annual variability were quantified by calculating Pearson's correlations, mean bias, mean absolute bias and the ratio of the standard deviations (SDs) for each of 4 pairs of time series (Table 2). Each statistic formulation that used provides a different information about the ability of MODIS to reproduce the variability recorded to stations. Mean bias reveals the eventual tendency of MODIS to systematically under- or overestimate in situ data; mean absolute bias gives a concise measure of the distance between the 2 time series and; the ratio of SDs gives an indication of how much more $(\alpha>1)$ or less $(\alpha<1)$ variable MODIS data are with respect to stations (Bernardello et al., 2016). The combined information provided by these statistic formulations, allow to evaluate particular aspects that are not revealed when considered individually. For example, when the mean bias and mean absolute bias are of a similar magnitude in absolute value, the systematic under- or overestimation of MODIS can be corrected by that amount, as long as it is $>0.50^{\circ} \mathrm{C}$ which is the accuracy of the data loggers in stations (Bernardello et al., 2016). 
Table 2. Statistic formulations that used and symbols that adopted in the figures. M: MODIS; DL: Data Logger; $\mathrm{n}$ : number of days in the time series

\begin{tabular}{|c|c|c|}
\hline Metric & Symbol & Definition \\
\hline Pearson's Correlation & r & Between $M$ and $D L$ \\
\hline Mean bias & $\delta$ & $\frac{1}{n} \sum(M-D L$ \\
\hline Mean absolute bias & $\Delta$ & $\frac{1}{n} \sum \mid M-D L$ \\
\hline Ratio of Standard Deviations (SD) & $\alpha$ & $\frac{S D(M)}{S D(D L)}$ \\
\hline
\end{tabular}

As mentioned, the time series defined according overall variability, inter-seasonal variability and interannual variability respectively. For overall variability, MODIS time series were compared the respective data logger time series $T_{\text {air. }}$ For intra-seasonal variability, as value pairs (MODIS-Logger) for analysis are chosen summer and winter respectively. Finally, for inter-annual variability and to obtain anomalies for each time series, a comparison of each year with 2011 measurements for both MODIS and logger data has been done.

\section{RESULTS AND DISCUSSION}

\subsection{Overall performance and variability}

When examining the data on an annual basis, a marked seasonality characterized all observational locations. The annual thermal amplitude in daily mean surface temperature ranging from $12.0^{\circ} \mathrm{C}$ in 2014 at Prodromos station to $20.8^{\circ} \mathrm{C}$ in 2013 at Larnaca station. The mean minimum value observed in Prodromos at $2013\left(-0,5^{\circ} \mathrm{C}\right)$ and mean maximum at Athalassa in $2012\left(33.0^{\circ} \mathrm{C}\right)($ Table 3). The correlation coefficient $(\mathrm{r})$ between the MODIS 1-km land surface temperature and $T_{\text {air }}$ from data loggers was higher than 0.91 for all locations indicating a high level of agreement. All biased values are positive which means that the MODIS LST products are overestimated compared with the ground-measured data.

Table 3. Surface temperature recorded by data loggers and statistics for each examined year

\begin{tabular}{|c|c|c|c|c|c|c|c|c|c|c|c|c|c|c|c|}
\hline No & Name & Year & Mean & SD & SE & Min & Max & No & Name & Year & Mean & SD & SE & Min & Max \\
\hline \multirow[t]{5}{*}{1} & PAFOS & 2011 & 19.6 & 5.4 & 1.6 & 9.8 & 28.2 & 3 & LARNACA & 2011 & 19.8 & 6.4 & 1.8 & 7.8 & 29.6 \\
\hline & & 2012 & 20.5 & 5.8 & 1.7 & 9.2 & 29.7 & & & 2012 & 20.3 & 6.7 & 1.9 & 8.2 & 30.7 \\
\hline & & 2013 & 20.0 & 5.7 & 1.6 & 6.0 & 28.8 & & & 2013 & 20.8 & 6.3 & 1.8 & 5.6 & 30.2 \\
\hline & & 2014 & 20.5 & 5.2 & 1.5 & 12.3 & 28.3 & & & 2014 & 20.6 & 5.5 & 1.6 & 12.5 & 28.4 \\
\hline & & 2015 & 19.9 & 5.5 & 1.6 & 5.8 & 28.4 & & & 2015 & 20.2 & 6.4 & 1.8 & 4.3 & 30.7 \\
\hline \multirow[t]{5}{*}{2} & ATHALASSA & 2011 & 19.6 & 7.5 & 2.2 & 6.8 & 31.8 & 4 & PRODROMOS & 2011 & 12.1 & 7.0 & 2.0 & 3.2 & 24.9 \\
\hline & & 2012 & 20.0 & 7.6 & 2.2 & 6.2 & 33.0 & & & 2012 & 14.0 & 7.9 & 2.3 & -1.7 & 28.2 \\
\hline & & 2013 & 20.2 & 7.7 & 2.2 & 3.8 & 31.2 & & & 2013 & 14.9 & 7.4 & 2.1 & -5.0 & 26.0 \\
\hline & & 2014 & 20.1 & 6.9 & 2.0 & 10.3 & 32.1 & & & 2014 & 12.0 & 7.1 & 2.1 & 0.8 & 25.0 \\
\hline & & 2015 & 19.7 & 7.7 & 2.2 & 7.5 & 31.8 & & & 2015 & 12.7 & 7.2 & 2.1 & 1.1 & 24.4 \\
\hline
\end{tabular}

Mean absolute bias values for all locations are between $1.26^{\circ} \mathrm{C}$ and $4.13^{\circ} \mathrm{C}$, and the ratio between MODIS and data logger SDs was close to 1 (between $1.03^{\circ} \mathrm{C}$ and $1.36^{\circ} \mathrm{C}$ ). Therefore, the combined information provided by the statistics, point to similar seasonal variability between the series with some although systematic towards overestimation of seasonal fluctuations of surface temperature by MODIS (Figure 3). 

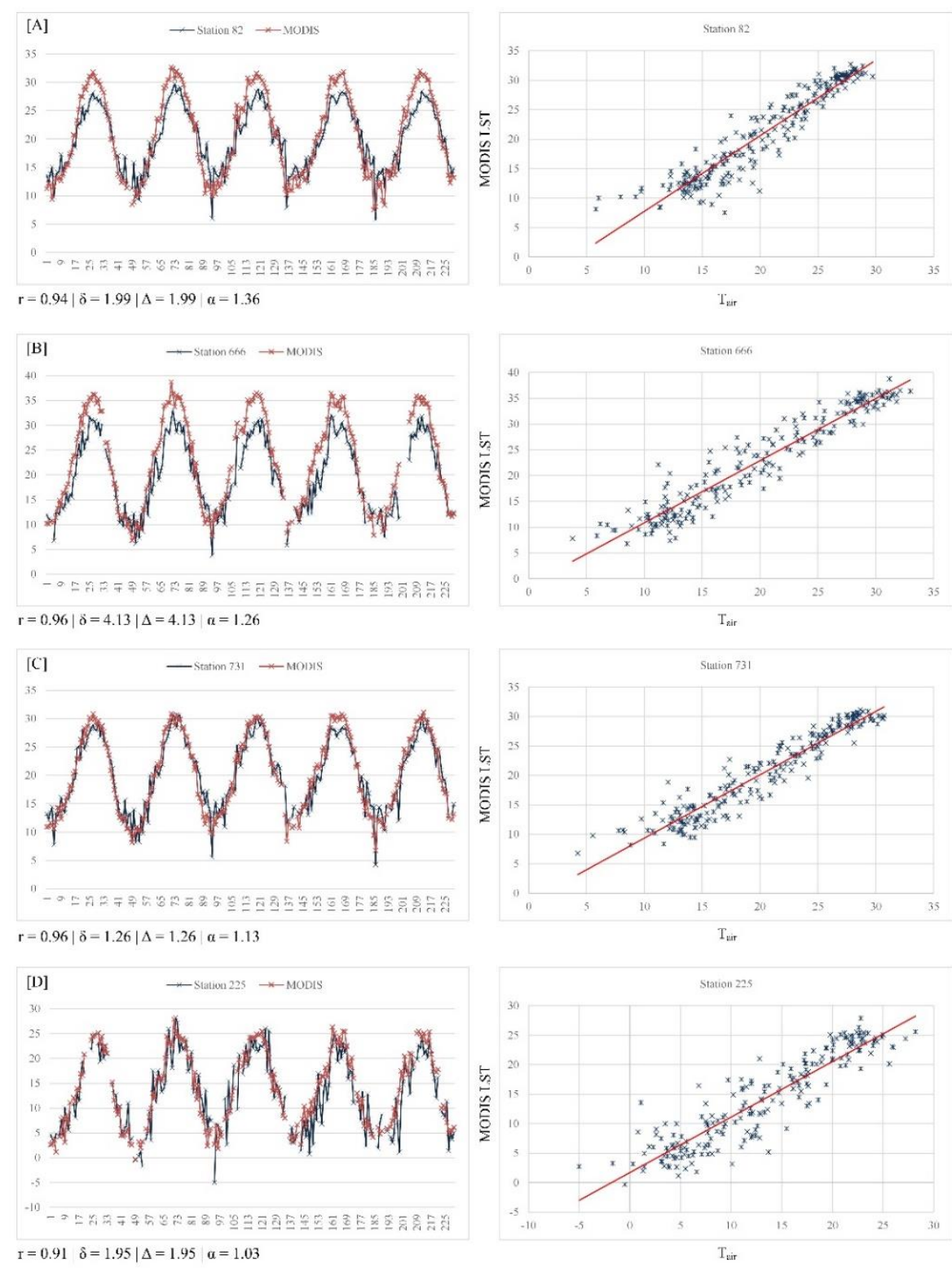

Figure 3. Comparison of overall variability between data logger $T_{\text {air }}$ values (black lines) and MODIS LST (red lines). Statistics for each location are noted above each panel for all stations: $[A]=$ Pafos; $[B]=$ Athalassa;

$$
[C]=\text { Larnaca; } \text { and }[D]=\text { Prodromos }
$$

\subsection{Intra-seasonal variability}

Figure 4 shows that correlations between the 2 series of 8-day LST and Tair at worm season were always significant and ranged from 0.68 at Prodromos station to 0.84 at Paphos station. MODIS tended to systematically overestimate surface temperature with a mean bias between $2.85^{\circ} \mathrm{C}$ (station \#225) and $6.71^{\circ} \mathrm{C}$ (station \#666). The ratio of SDs during summer season, pointed to a general tendency of MODIS to underestimate intra-seasonal variability with values ranging between 0.72 (station \#225) and 0.92 (station \#82). In the other hand, correlations of those 2 series over cold season were almost significant with the values of the coefficient to be lower to those of summer and ranging from 0.42 (station \#82) to 0.65 (station \#731). MODIS tended to underestimate surface temperature in 2 stations with mean bias between $-0.71^{\circ} \mathrm{C}$ (station $\# 82$ ) and $-0.26^{\circ} \mathrm{C}$ (station \#731) and mean absolute bias to be lower than summer. For the rest 2 stations (station \#225 \& station \#666) MODIS tended to overestimate surface temperature with mean bias ranging from 0.69 to $1.14^{\circ} \mathrm{C}$ and mean absolute bias to be also lower than summer. Despite summer season, MODIS tended to underestimate intra-seasonal variability in 2 coastal area stations and overestimate it in other 2 with SDs ratio ranging between 0.58 (station \#225) and 0.83 (station \#666). 

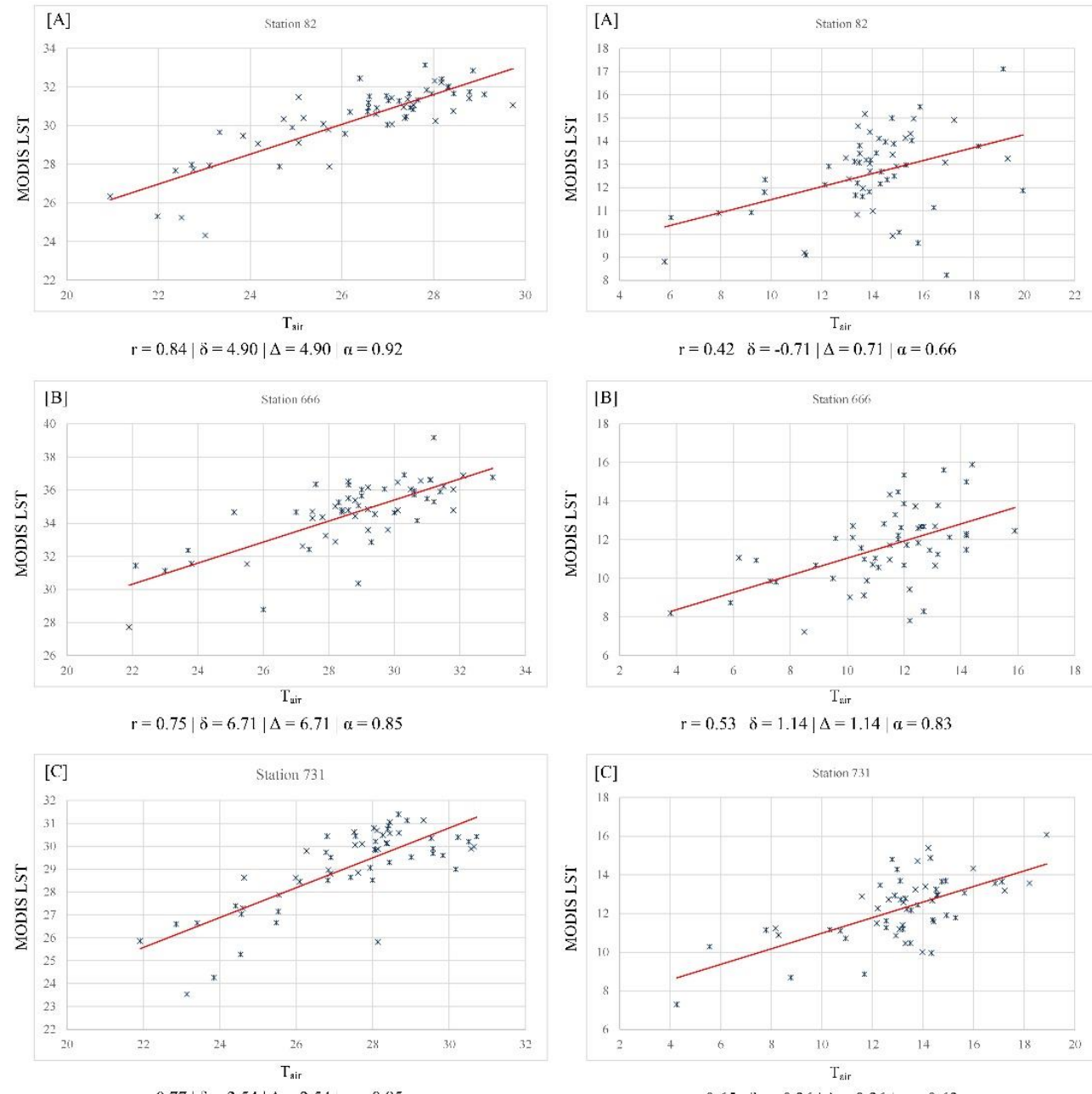

$\mathrm{r}=0.77|\delta=2.54| \Delta=2.54 \quad a=0.85$

$r=0.65 \quad \delta=-0.26|\Delta=0.26| a=0.62$
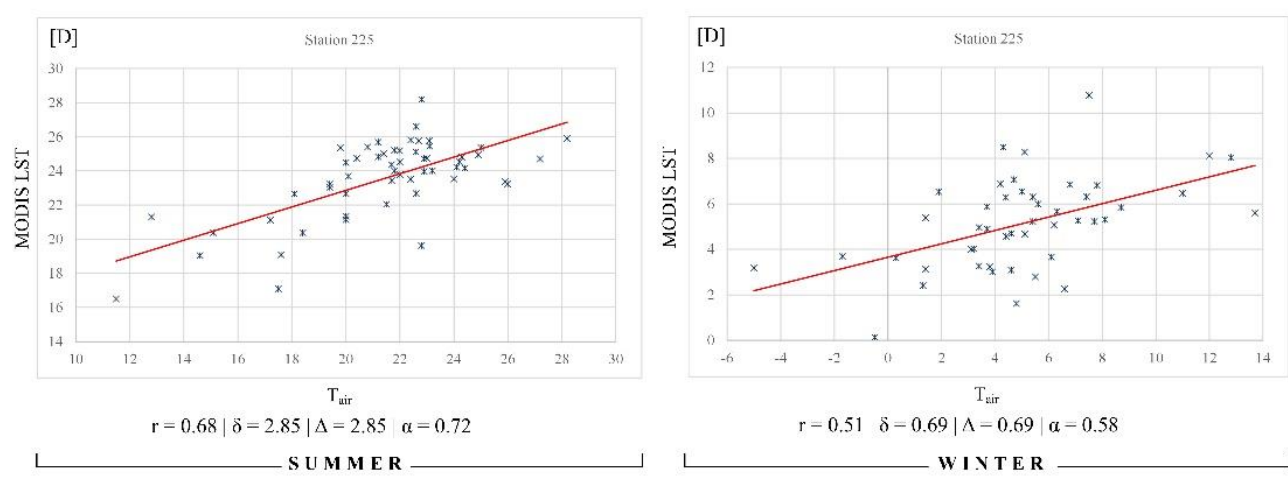

Figure 4. Comparison of intra-seasonal variability between data loggers Tair and MODIS LST. Data were selected left/right a summer/winter LST reference to logger time series. Statistics for each comparison is noted above each panel for all stations: $[\mathrm{A}]=$ Pafos; $[\mathrm{B}]=$ Athalassa; $[\mathrm{C}]=$ Larnaca; and $[\mathrm{D}]=$ Prodromos

\subsection{Intra-annual variability}

The examination of LST and Tair differences among the years and thus the description of any anomalies derived from the comparison of each year data source with 2011 respectively. Anomaly LST and anomaly Tair values are ranging from $-8.8^{\circ} \mathrm{C}$ to $9.4^{\circ} \mathrm{C}$. Figure 5 shows that the correlation coefficients were lower than the overall variability but were always significant and ranged from 0.38 (station \#82) to 0.47 (station \#666). There was no indication of a tendency for MODIS to systematically under- or overestimate the amplitude of the inter-annual variability with mean bias ranking from -1.10 to $0.05^{\circ} \mathrm{C}$. Mean absolute bias was lower than the accuracy of the data loggers in all points except station \#225. The ratio of SDs was between 0.60 at Prodromos station and 0.76 at Paphos station. 

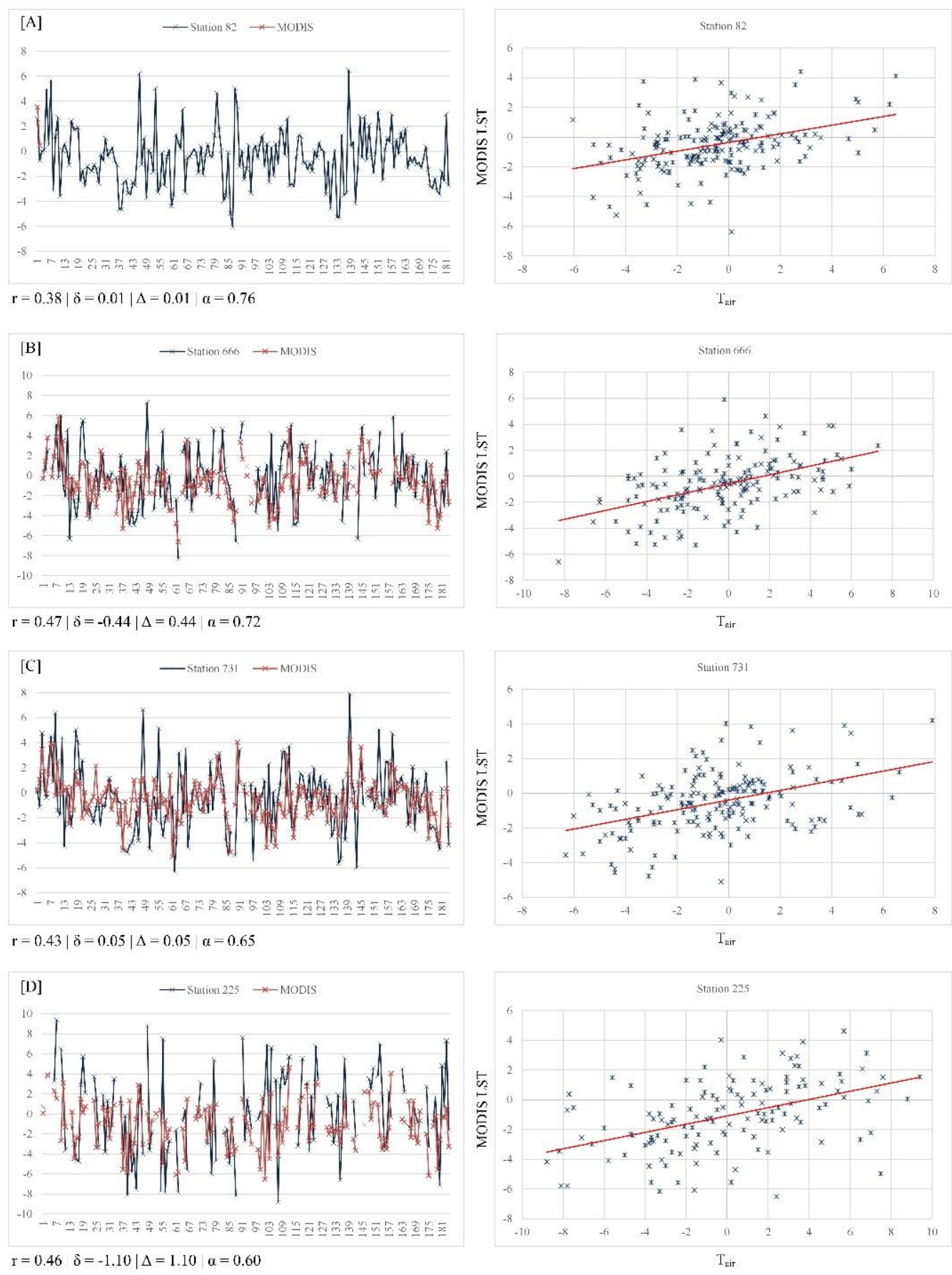

Figure 5. Comparison of inter-annual variability between data loggers Tair (black line) and MODIS LST (red line). Statistics for each comparison is noted above each panel for all stations: $[A]=$ Pafos; $[B]=$ Athalassa; $[C]=$ Larnaca; and $[D]=$ Prodromos

Furthermore, as indicated from the analysis, the station of Prodromos presents both maximum positive values in February of $2012\left(\sim 9.40^{\circ} \mathrm{C}\right)$ and maximum negative values in April of $2014\left(\sim-8.80^{\circ} \mathrm{C}\right)$ from the measurements derived from data logger. In the other hand, from MODIS measurements, the station of Athalassa presents both maximum positive values in Feb of $2012\left(\sim 5.90^{\circ} \mathrm{C}\right)$ and maximum negative values in May of $2013\left(\sim-6.60^{\circ} \mathrm{C}\right)$.

Figure 6 presents anomaly maps as derived with the comparison of mean LST of each year with 2011 respectively. LST anomaly values are ranging from $-2.0^{\circ} \mathrm{C}$ to $2.0^{\circ} \mathrm{C}$ with blue color indicating negative changes and red positive LST changes. As it shown, 2012 presents the minimum ALST values indicating negative LST change which is located mainly among Pentadaktylos and Troodos range. Overall, an increase trend of surface 
temperature is presented from 2013 to 2015 with 2014 to present the maximum ALST values indicating the increase of surface temperature over the study area.
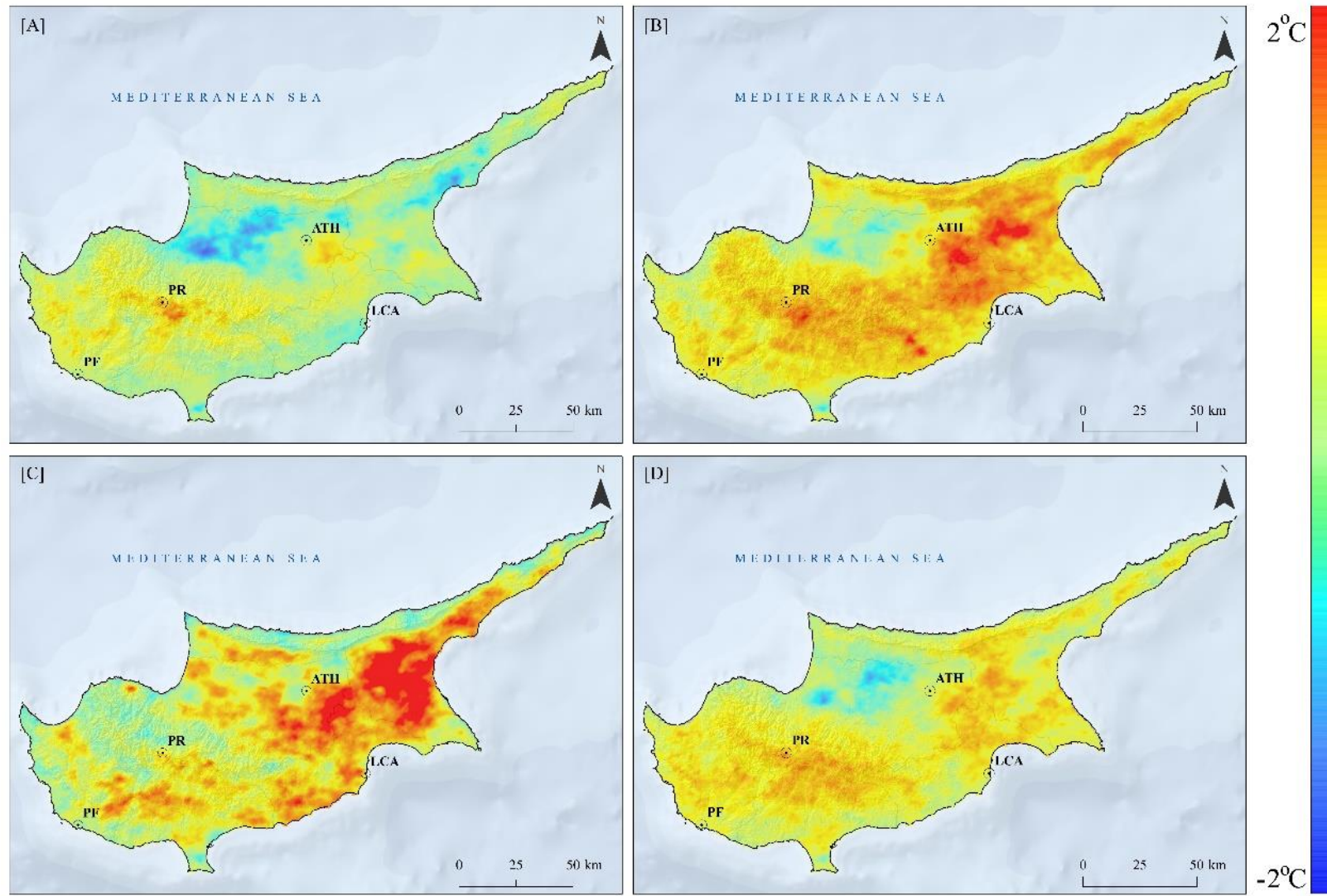

Figure 6. Yearly mean LST anomaly values for: $[A]=2012$ Vs 2011; $[B]=2013$ Vs 2011; $[C]=2014$ Vs 2011; and $[D]=2015$ Vs 2011

\section{CONCLUSIONS}

In order to assess the potential of remotely sensed data to estimate air temperature, a spatio-temporal analysis was realized to compare MODIS 8-day LST (both day and night) on board Aqua and Terra sun synchronous satellites with Tair observations from 4 stations locating in south part of Cyprus.

The major findings of this research can be summarized in some key points. First, LST does not exactly match with ground Tair measurements, as expected, but a strong correlation $(r>0.96)$ between the two sets of measurements is presented. The weaker correlations obtained between Tair and LST are: (a) from a station located near shoreline (station of Paphos) due to the effect of the different materials on the ground and near shore pixels and (b), from station located in mountainous area probably due to the effect of snow in cold season. Secondly, MODIS presents a systematic towards overestimation of seasonal fluctuations of surface temperature is some stations. This feature was likely caused by the instantaneous nature of satellite data that may have introduced short-term sub-daily variability resulting in a more variable time series relative to the daily average of hourly logger data (Bernardello et al., 2016). In addition, for intra-seasonal temperature variability MODIS presents a tendency to overestimate the variability in summer despite in cold seasons where a tendency to underestimate the variability is presented. The differences are largely due to the nature and state of the surfaces being sensed within the MODIS pixels (e.g. vegetation, bare rock, snow, surface waters, and distance from coast line). In the other hand, examining temperature anomalies, MODIS proved to be able to capture inter-annual variability without any systematic tendency towards either under- or overestimation and with mean absolute bias very similar (except Prodromos station). Moreover, the mean 8-day LST yields stronger correlation with Tair when the data from the two satellites are combined than when values are taken separately. This high correlation suggests that LSTs can be used and applied from regional to continental scale. The temporal and spatial coverage as well as the $1 \mathrm{~km}^{2}$ footprint are great advantages for improving mapping precision and for monitoring the LST variation. Another key point, is that LST and $T_{\text {air }}$ show a high degree of temporal coherence and on broad spatial and temporal scales they follow the same 
trajectory. The only concern, is that ground measurements are discrete in space, while satellite-derived LSTs are discrete in time. The scaled mismatch issue in both space and time must be consider. Furthermore, the averaged logger data over 8-day period probably resulted in less variable logger time series even if the general distribution of temperature did not show considerable changes.

Nevertheless, further investigation is needed in order to retrieve more accurate values in terms of spatial and temporal scale. Additional data must be gathered and extend to a decay span of a daily interval for both ground and satellite derived data. Moreover, higher density of stations where it is possible is needed to exclude more pronounced differences between MODIS and in situ temperatures, to investigate thermal variability and explore the effect of other parameters on LSTs. Bernali et al. (2012) used environmental and climate data to characterize the stations and to define to which extent they were representative of their study region. They took also into consideration the latitude distribution of the stations and their elevation. They highlight that wind velocity and vegetation are very important factors that influence the energy balance in the land-atmosphere system, thus, influence the LST-Tair relation. Wang, (2005) demonstrated that there are no significant differences in the coefficients of different types of materials, except for ice, water and snow, although different materials influence the coefficients. Some others (Wan et al., 2004; Wang et al., 2008; Zhu et al., 2013) use the factors of surface temperature, humidity, wind speed, Normalize Difference Vegetation Index (NDVI), Corine Land Cover, and soil moisture, to analyze their contribution to errors in MODIS LST products. Yu et al. (2014) performed spatial heterogeneity analysis using a semi-variance analysis method, to analyze effects on the validation results based on a higher resolution land surface temperature data retrieved from Landsat Thematic Mapper (TM) images. Final, Ermida et al, (2014) tabulates the possible sources of LST differences highlighting the difficulty to ascertain the actual accuracy of each retrieval. Discrepancies in LST products may be associated to differences (i) in the top-of-atmosphere measurements (sensor calibration, spatial resolution), (ii) in the algorithm and auxiliary data used for atmospheric and surface emissivity correction, (iii) in cloud mask, and (iv) in angular anisotropy.

In summary, LST is a key variable for climatological and environmental studies. MODIS-derived LST is a viable data source for monitoring the surface thermal regime in local and continental scale and for modeling seasonal or annual variability of the surface temperature. It proved to be reliable source especially for studies requiring temperature reconstruction in areas with lack of observational stations.

\section{ACKNOWLEDGMENTS}

The authors would like to thank the Department of Meteorology of the Ministry of Agriculture, Rural Development and Environment of Cyprus, for providing the data set from observational stations and offered their valuable help and remarks for this research.

\section{REFERENCES}

Anderson, M., Norman, J., Kustas, W., Houborg, R., Starks, P., \& Agam, N. (2008). A thermal-based remote sensing technique for routine mapping of land-surface carbon, water and energy fluxes from field to regional scales. Remote Sensing of Environment, 112(12), 4227-4241. [Crossref]

Anderson, S. (2002). An evaluation of spatial interpolation methods on air temperature in Phoenix, AZ. Department of Geography, Arizona State University Tempe, 85287, 104.

Benali, A., Carvalho, A. C., Nunes, J. P., Carvalhais, N., \& Santos, A. (2012). Estimating air surface temperature in Portugal using MODIS LST data. Remote Sensing of Environment, 124, 108-121. [Crossref]

Bernardello, R., Serrano, E., Coma, R., Ribes, M., \& Bahamon, N. (2016). A comparison of remote-sensing SST and in situ seawater temperature in near-shore habitats in the western Mediterranean Sea. Marine Ecology Progress Series, 559, 21-34. [Crossref]

Caparrini, F., Castelli, F., \& Entekhabi, D. (2004). Variational estimation of soil and vegetation turbulent transfer and heat flux parameters from sequences of multisensor imagery. Water Resources Research, 40(12). [Crossref]

Crosson, W. L., Al-Hamdan, M. Z., Hemmings, S. N. J., \& Wade, G. M. (2012). A daily merged MODIS AquaTerra land surface temperature data set for the conterminous United States. Remote Sensing of Environment, 119, 315-324. [Crossref] 
Ermida, S. L., Trigo, I. F., DaCamara, C. C., Göttsche, F. M., Olesen, F. S., \& Hulley, G. (2014). Validation of remotely sensed surface temperature over an oak woodland landscape\textemdash The problem of viewing and illumination geometries. Remote Sensing of Environment, 148, 16-27. [Crossref]

Florio, E. N., Lele, S. R., Chang, Y. C., Sterner, R., \& Glass, G. E. (2004). Integrating AVHRR satellite data and NOAA ground observations to predict surface air temperature: a statistical approach. International Journal of Remote Sensing, 25(15), 2979-2994. [Crossref]

Georgiou, A., \& Akçit, N. (2016). Investigation of Sea Surface Temperature (SST) anomalies over Cyprus area. In K. Themistocleous, D. G. Hadjimitsis, S. Michaelides, \& G. Papadavid (Eds.), Fourth International Conference on Remote Sensing and Geoinformation of the Environment (RSCy 2016). inproceedings, SPIE. [Crossref]

Hachem, S., Duguay, C. R., \& Allard, M. (2012). Comparison of MODIS-derived land surface temperatures with ground surface and air temperature measurements in continuous permafrost terrain. The Cryosphere, 6(1), 51-69. [Crossref]

Hengl, T., Heuvelink, G. B. M., Tadić, M. P., \& Pebesma, E. J. (2011). Spatio-temporal prediction of daily temperatures using time-series of MODIS LST images. Theoretical and Applied Climatology, 107(1-2), 265-277. [Crossref]

Kustas, W. P., \& Norman, J. M. (1996). Use of remote sensing for evapotranspiration monitoring over land surfaces. Hydrological Sciences Journal, 41(4), 495-516. [Crossref]

Li, Z.-L., Tang, B.-H., Wu, H., Ren, H., Yan, G., Wan, Z., ... Sobrino, J. A. (2013). Satellite-derived land surface temperature: Current status and perspectives. Remote Sensing of Environment, 131, 14-37. [Crossref]

Michaelides, S. C., Tymvios, F. S., \& Michaelidou, T. (2009). Spatial and temporal characteristics of the annual rainfall frequency distribution in Cyprus. Atmospheric Research, 94(4), 606-615. [Crossref]

Mostovoy, G. V, King, R. L., Reddy, K. R., Kakani, V. G., \& Filippova, M. G. (2006). Statistical Estimation of Daily Maximum and Minimum Air Temperatures from MODIS LST Data over the State of Mississippi. GIScience \& Remote Sensing, 43(1), 78-110. [Crossref]

Nemani, R., Pierce, L., Running, S., \& Goward, S. (1993). Developing Satellite-derived Estimates of Surface Moisture Status. Journal of Applied Meteorology, 32(3), 548-557. [Crossref]

Vancutsem, C., Ceccato, P., Dinku, T., \& Connor, S. J. (2010). Evaluation of MODIS land surface temperature data to estimate air temperature in different ecosystems over Africa. Remote Sensing of Environment, 114(2), 449-465. [Crossref]

Vogt, J. V, Viau, A. A., \& Paquet, F. (1997). Mapping regional air temperature fields using satellite-derived surface skin temperatures. International Journal of Climatology, 17(14), 1559-1579. [Crossref]

Wan, Z. (1999). MODIS land-surface temperature algorithm theoretical basis document (LST ATBD). Institute for Computational Earth System Science, Santa Barbara, 75.

Wan, Z. (2008). New refinements and validation of the MODIS Land-Surface Temperature/Emissivity products. Remote Sensing of Environment, 112(1), 59-74. [Crossref]

Wan, Z., Wang, P., \& Li, X. (2004). Using MODIS Land Surface Temperature and Normalized Difference Vegetation Index products for monitoring drought in the southern Great Plains, USA. International Journal of Remote Sensing, 25(1), 61-72. [Crossref]

Wang, K. (2005). Estimation of surface long wave radiation and broadband emissivity using Moderate Resolution Imaging Spectroradiometer (MODIS) land surface temperature/emissivity products. Journal of Geophysical Research, 110(D11). [Crossref]

Wang, W., Liang, S., \& Meyers, T. (2008). Validating MODIS land surface temperature products using longterm nighttime ground measurements. Remote Sensing of Environment, 623-635. [Crossref]

Yu, W., Ma, M., Wang, X., Geng, L., Tan, J., \& Shi, J. (2014). Evaluation of MODIS LST Products Using Longwave Radiation Ground Measurements in the Northern Arid Region of China. Remote Sensing, 6(11), 1149411517. [Crossref]

Zhu, W., Lu, A., \& Jia, S. (2013). Estimation of daily maximum and minimum air temperature using MODIS land surface temperature products. Remote Sensing of Environment, 130, 62-73. [Crossref] 